\title{
Learning Embedded in Structures: Facilitating Systems for Learning within Offshore Drilling Operations
}

\author{
Trygve J. Steiro \\ Norwegian University of Science and Technology, Norway \\ Trygve.j.steiro@ntnu.no
}

Tor Erik Evjemo

SINTEF Digital, Norway

Torerik.evjemo@sintef.no

Purpose: The current study examines the contribution of formalised planning to ensure success in drilling operations seen in the light of organizational learning theory.

\begin{abstract}
Methodology: The applied methodology is observational fieldwork including interviews, document studies and informal talks on a drilling rig on the Norwegian continental shelf conducted by the authors lasting for 6 days including 120 hours of observational fieldwork.
\end{abstract}

Findings: It is described how procedures are adapted to the specific context in which a job is performed and how the adaption of procedures is integrated into the formalised organisational learning processes.

\begin{abstract}
Originality: Organizational learning is seen through praxis and the dialectical relationship between formalised work and work as done, that is, the formal structures involved when planning work and how procedures materialise during actual work, and the relationship to learning per se.
\end{abstract}

Keywords: organizational learning, formalised planning, drilling operations

\section{Introduction}

The Normal Accident perspective (Perrow, 1984) claims that the degree to which technology is characterised by tight coupling and/or complex interactions have implications for the need for centralised versus decentralised control of the operations. A system is tightly coupled if disturbances propagate rapidly throughout the system, and there is little natural slack or redundancy that allows people to improvise ways to contain the disturbances. Complex interactions cause systems to behave in unexpected ways and may catch personnel by surprise. A system with high interactive complexity can be effectively controlled only by a decentralised organisation; for example, highly interactive technologies generate many non-routine tasks. Such tasks are difficult to program or standardise. Therefore, the organisation has to provide operators at the sharp end considerable discretion and encourage direct interaction between them. On the other hand, a system with tight couplings can be effectively controlled only by a highly centralised organisational structure. If disturbances appear, a fast and coordinated response is required, and this calls for centralisation. The current study is rooted in the tension between interactive complexity that requires decentralised organisation and close links that require centralisation, that is, planning from onshore that are to be executed in operations offshore.

Another aspect is that parallel activities may cause conflict, so strictly centralised coordination is needed to avoid conflicts between activities. Rosness et al. (2010) point out that there is a dilemma if a system is characterised by high interactive complexity and tight couplings (Rosness et al., 2010:49). According to Perrow's (1984) logic, the organisation needs to be both centralised and decentralised. This paper examines aspects of how this dilemma is handled on an offshore drilling rig, taking the application of planning per se, including procedures, as a 
starting point seen in the framework of learning. Ose and Steiro (2020) studied the planning processes of drilling operations and found learning to be a significant enabling factor for ensuring successful operations.

In a study by Bourrier (1998), two French and two US nuclear power plants were studied, showing how formal procedures frequently needed to be adjusted. However, the processes in the French nuclear power plants were quite different from the US nuclear power plants. For example, the French personnel adjusted the procedures on the floor without the management knowing - the maintenance personnel noted and shared the adjustment in a notebook. In the two US nuclear power plants, there was more verbatim compliance. When challenges were faced, they informed the foreman and asked for a new work order when the task was unclear. In the US plants, the middle management with the formal authority to authorise modifications of procedures was much more available. In the French, on the other side, they were less available due to staff reductions in middle management. Consequently, secret practices and pockets of private information developed, and the organisation as a whole failed to learn from successful adaptations. However, the US power plants could be termed self-correcting organisations because they had mechanisms such as availability and close cooperation to reconcile prescribed work and 'work as done,' and to make the knowledge of the workers available to the greater organisation (Bourrier, 1998). Both the two French plants and the two US plants could be termed machines from the perspective of Morgan's (1980) metaphors on organisations. However, the US plants had clearly stronger evidence of brain attributes, demonstrating the metaphors as perspectives of organisations and not seen as mutually exclusive, but rather that 'different metaphors can constitute and capture the nature of organisational life in different ways, each generating powerful, distinctive, but essentially partial kinds of insight (Morgan, 1980: 612).

Offshore drilling operations are considered a high-risk activity demanding centralised control in line with (Perrow, 1984) to ensure safe operations. At the same time, crews may confront considerable interactive complexity in, for example, drilling operations. We assumed that the combination of tight coupling and interactive complexity might create operating and learning challenges similar to those facing a nuclear power plant, albeit less severe. In particular, the need for centralised control could lead to a strong reliance on procedures, whereas the interactive complexity could create situations where the procedures could not be readily applied. We wanted to explore the means to create a self-correcting organisation under these circumstances within a drilling operational context.

Offshore life has been considered a 'different world' (Hellesøy, 1985). The crews operate on a 2/4 schedule, meaning that they are two weeks offshore at work and then four weeks at home (onshore). The crews typically start on a night shift rotating after one week to the day shift (Hellesøy, 1985). Sætren and Laumann (2014) point out that they work a 12-hour shift every day, and they usually share all the meals together. This means they have a good opportunity to get to know each other quite well. The 'vacant period' between working hours can also be subject to company courses and training. In total, six crews are needed to operate each rig. Offshore installation managers (OIMs) are on duty 24/7, meaning that there are three OIMs on each rig. The same holds for the safety officer. This means that handover, knowledge, and experience transfer are a challenge and very interesting from the perspective of organisational learning. But it also means that it takes time before the knowledge is distributed and that there might be a time and context challenge when transferring experience.

This paper focuses on drilling operations by exploring the implementation of formalised plans per se, for example, the drilling plan, including procedures and guidelines concerning organisational learning on-board the drilling rig. 
The following research questions will be answered:

- How is learning structured through formalised planning?

- How can actual learning be conceptualised to improve our understanding of and strengthen applied organisational learning on a drilling rig?

\section{Theoretical considerations}

\section{The role of Plan-Do-Study-Act (PDSA) within a machine bureaucracy}

According to Mintzberg (1979), a machine bureaucracy can be defined as a management structure with a high degree of formalisation and specialisation. In a machine bureaucracy, decisions are made at the top level and mechanically carried out at the lower levels. The design of a machine bureaucracy tends to be as follows: highly specialised, routine operating tasks, very formalised procedures in the operating core, a proliferation of rules, regulations, and formalised communication, large-sized units at the operational level, reliance on the functional basis for grouping tasks, relatively centralised power for decision-making, and an elaborate administrative structure with sharp distinctions between line and staff (Mintzberg, 1979). We see a similar organisational understanding in Morgan (2006) through his machine metaphor, where precision, efficiency, and predictability are key characteristics based on a bureaucratic and functional specialisation of tasks and responsibilities.

The organisation of drilling operations on-board an offshore drilling rig shares many of these characteristics. The rationale for this is that drilling companies operate in rather stable conditions with a less dynamic environment (Burns \& Stalker, 1961; 1960). Mintzberg's (1979) classification can be viewed as an overall typology. However, during drilling operations, unforeseen conditions do occur, and more flexible patterns of organising are needed, in line with LaPorte and Consolini (1991) and being able to adapt and execute double-loop learning (Argyris \& Schön, 1978: 1996). The same holds for a machine bureaucracy like an aircraft carrier where the main concern is to decide what Standard Operating Procedures (SOP) to apply regarding a given situation (LaPorte \& Consolini, 1991). The capability to respond effectively in novel and unexpected situations plays a crucial role in these processes (Simon, 1991).

Planning is essential for machine bureaucracies like drilling organisations. For example, the concept of Plan, Do, Study, Act (PDSA) was invented in organisations like machine bureaucracies (Deming, 2000; Womack, 1990). PDSA is a quality improvement system. PDSA is a process that follows four steps similar to a scientific methodology (Sobek \& Smalley, 2008; Lillrank \& Kano,1989). The PDSA pillars can be explained as follows. Firstly, planning is initiated when a potential for improvement is identified; plans need to be developed for new goals to be achieved. Secondly, do is the execution of the plans. Thirdly, at the same time, data must be collected to be able to evaluate the effort. Therefore, a study is performed after a while to assess plans and routines. Does the effort lead to actual improvement? Plans and routines need to be refined to be more accurate. The study is about assessing whether the effects of the implementation are sufficiently verified (Sobek \& Smalley, 2008). Fourthly, the act is the last phase, and when eventual changes have been made, the process continues. PDSA continues further.

In our second case, the drilling entrepreneur reported that they had used a PDSA system since 2011. Imai (1986) points to the importance of spreading the improvements. Otherwise, the results will remain local and not spread to a wider audience (Sobek \& Smalley, 2008). Structural problem-solving is an important fundament in improvement initiatives. PDSA/A3 is a structural problem-solving method that has become a symbol for the learning process improvement efforts it represents (Berger, 1997; Deming, 2000). A3 is based on an A3 sheet format that covers the problem description and the solution visually. The idea is that a visual A3 illustration can easily 
be communicated and closed when the improvement is standardised (Shook, 2008; Sobek \& Smalley, 2008).

A basic precondition for continuous improvement initiatives is to create an organisational learning environment (Bessant et al., 2001; Wu \& Chen, 2006). However, programs like LEAN and most continuous improvement programs depend on scaffolds on standard operating procedures (SOP) as a central and important part of the philosophy and methodology. However, in several cases, these standards fail to consider how individual insight and experiences are transformed into action, thereby potentially limiting learning per se (March \& Olsen, 1975; Kim, 1998).

\section{Organisational plans and the relation to practice}

According to Suchman's concept of situated action $(1987,2007)$, plans do not determine action; they are merely resources for action. Suchman's original work illustrates how users trying to follow expert guidance systems on photocopiers based on the idea of intelligent machines failed. She challenged the idea within artificial intelligence (AI) and cognitive science at the time that machines could be designed to understand users' goals and thus guide humans to meet those goals by following a predetermined plan. Suchman (1987) showed the reasoning behind designing an ideal plan grounded in a presumption of compliance that did not correspond to how the plan was carried out in practice by the end-users themselves. Suchman (1987) argued for the need to understand the role of plans in everyday work, acknowledging that plans are static constructions while the work context is ever-changing, and we rely on interpretation and improvisation to solve everyday challenges. Her work has had a major impact on research traditions like human-computer interaction (HCI) and the more socially oriented computersupported cooperative work (CSCW). However, and perhaps strangely, her work is rarely referred to within the safety research literature, although she is one of the pioneers with regard to problematising the application of plans relative to actual work practices. Steiro, Thevik, \& Albrechtsen (2017) concluded that both compliance and resilience are equally important for successful operations and that a certain degree of both is required.

Hollnagel (2013) argues that the traditional view on safety, which he labels Safety-I, pays attention to the things that go wrong but fails to study successful performance. Thus, unwanted events need to be contained and kept at a minimum by minimising errors via identifying their causes. By designing barriers and favouring compliance regarding plans, procedures, and regulations, the Safety-I perspective mainly addresses work as imagined to ensure safety (Hollnagel et al., 2013). On the other hand, safety can be understood based on what goes well, for example, what key stakeholders deem as successes regarding naturally occurring work practice. This approach, which Hollnagel (2013) labels Safety-II, requires attention to work as done since it implies that people make sensible adjustments to emerging demands related to their particular activity at the moment. Importantly, and in conjunction with Suchman's (1987; 2007) original work, this view on safety acknowledges that successful work accomplishment does not rely entirely on strict compliance with formalised plans and procedures; informal work factors are as well important.

Consequently, studying actual work is very important as input to understand why adjustments to standard operating procedures (SOPs) are sometimes also necessary as efficiencythoroughness trade-offs (ETTO) (Hollnagel, 2009) or to examine whether there is observed practical drift (Snook, 2002). Practical drift occurs when local practices are changed and drift away from the design concept, which assumes tight couplings between the different elements. Snook (2002) argues that this creates vulnerability if the system changes to a tightly coupled state, even if this state was anticipated in the design phase. In situations where tight couplings were assumed and necessary, there are loose couplings because of drift in practice away from 
the design idea (Snook, 2002). A similar example can be seen from the Longford accidents in 1998 (Hopkins, 2000), where practice drifted away from the design specification without being followed up and assessed centrally. An opposite approach is found in Bourrier's (1998) study.

\section{The institutionalisation of learning and the importance of showing humaneness}

Hernes and Irgens (2012) are critical of the organisational learning literature, claiming that too much focus has been on the mismatch between the expectations and outcomes. This is central, but studying continuity is equally important. Learning under continuity, the authors claim, requires an investment of effort, mindfulness, and preparedness for change, even if no perceptible change occurs. The idea that an organisation could learn and knowledge could be stored over time, was a key breakthrough, which was first articulated by Cyert and March (1963). A significant portion of the literature on organisational learning is founded on the individual learning theory, while social learning theory in the organisational learning literature has grown out of criticism of the individual approach regarding learning (Brandi \& Elkjaer, 2011). This individual learning contributes to a transformation process in the organisation (Pedler, Burgoyne, \& Boydell, 1990). Thus, organisations should adopt flat, decentralised organisational structures that facilitate open communication and dialogue (Pedler, Burgoyne, \& Boydell, 1999). Crossan, Lane, \& White (1999) also argue for a dynamic approach to organisational learning. This is in line with Huber (1991), Nonaka (1994,) \& Kim (1998). Crossan et al. (1999) further argue that, through interpreting, a group can share understanding and provide common meaning to phenomena and incidents. Here there is an integration both of concepts and practices. Institutionalising means that learning is embedded in plans, systems, and strategies which can be termed an organisation's infrastructure, and our focus is on institutionalised learning through practice. Jerez-Gomez et al. (2005) mention four dimensions regarding organisational learning ability. These are engagement from the management, system perspective, openness, and experimentation. Another aspect is procedural memory that refers to the stored experience, knowledge, and skills reproduced on a routine basis by organisational members (Cohen, 1991; Moorman and Miner, 1998; Singley \& Anderson, 1989). Morgan and Liker (2006) claim that the ability to learn through continual improvement is probably one of the most powerful approaches to competitiveness. Learning is also important in systems with the need to adjust and make sure that the organisation is not 'drifting into failure' (Snook, 2002).

Bolman and Deal (1989) observed early that total quality management (TQM) systems-of which PDSA is a part-are good examples of how the structural and human relations frames are complementary and that the combination is the precondition for the success of such systems. Jerez-Gomez et al. (2005) claim that openness and freedom to experiment are important for an organisation to achieve and maintain organisational learning ability. The dimension experimentation is linked to the employees' freedom to search for new ways to solve tasks, as is the freedom to take the experimental risk (Goh \& Richards, 1997; Jerez-Gomez et al., 2005). However, the authors may or may not have included high-risk industries, so the experimental risk should be approached carefully within this context. Huber (1991) commented early that the distribution of information influences the degree of organisational learning. If more people have access to information, there will be more and different interpretations of the same information. De Geus (1988) points out that scenario building enables multiple scenarios to be developed. But more importantly, it enables conversations between people inside the company and outsiders of the company that can be viewed as driving forces of a social, political, or technological nature. We argue that De Geus's (1998) findings can open up and invite for more double-loop learning (Argyris \& Schõn, 1978; 1996) and more focus on the trade-off between exploitation and exploration (March, 1991). Von Krogh, Ichijo, and Nonaka (2000) point out that the key 'quality of knowledge workers is their humanness' (2000:12). The goal of organisational learning is, therefore, to bring out this humanness (Nonaka, 1998). Humaneness 
arises in our relationships with others through communities (Plaskoff, 2011). The continuity of the community is ensured from a tactical point of view with activities such as meetings, distributing information, setting agendas, and facilitating gatherings. The second form is by mentoring, namely giving valuable directions (Plaskoff, 2011). Sætren and Laumann (2014) found a casual atmosphere and a respectful way of speaking to each other important, for example, when someone had or was about to do something not following a procedure. 'Their friendly and respectful interactions resulted in a perception of being taken seriously' (Sætren \& Laumann (2014:7). Moreover, Sætren and Laumann (2014) found that the crew relied on each other's collaborative skills and had confidence in each other's specific task performance. Open and respectful communication is imperative when pointing out deviations for professionals to be able to learn from this. Lagedec (1993) stresses that good communication and organisation need to be established during normal operation.

\section{Method}

We have conducted an observational and interview study where we have taken inspiration from the workplace studies genre as elaborated by Heath, Knoblauch \& Luff(2000), which implies understanding in depth how naturally occurring ordinary work is performed and organised, and the resources used by the participants when accomplishing work tasks. The starting point for our analysis is thus to study work practice, which means a focus on the actual accomplishment of drilling operations as it is performed in its natural environment on-board the rig. This type of study will thus be able to nuance the formalised descriptions of work as they are traditionally found in procedures and regulations (Suchman, 1987; 2007). Therefore, the importance of understanding the local context related to actual work performance on the rig cannot be overestimated. Such an understanding of real versus plan-based work execution is, as previously mentioned, acknowledged within the safety discipline as work as imagined versus work as done (Hollnagel, 2013). Ose \& Steiro (2020) found that the drilling discipline is accustomed to planning for contingencies, and it actively participates in meetings and reports dangerous elements to their oil company customer. This close collaboration was embedded in the processes, and possible outcomes were discussed.

Phase one (see Table 1) encompassed telephone interviews with ten persons employed on a drilling rig with over 15 years of service. The rig can be classified as medium-sized. The rig has operated on the Norwegian continental shelf for two to four years. This means that the crew had been quite newly employed and that they had recently used the time to familiarise themselves with both the technical and social sides of working on this particular drilling rig. The crew came from Norway, United Kingdom, Italy and Romania. It is operated by a relatively small drilling contractor. Phase two was conducted on a large drilling rig on the Norwegian continental shelf, the rig being one of the largest in the world in its class/type. This particular rig started operations less than five years ago, and an almost new organisation had to be built. The rig is operated by a large drilling contractor.

A qualitative and explorative approach was applied in our study of offshore drilling. The first phase consists of semi-structured interviews with various personnel belonging to a mid-sized drilling rig. In phase two, we conducted ethnographically inspired fieldwork on-board a large drilling rig during real operations offshore. The interviews gave us insight into drilling professionals perceptions and interpretations of actual work practice (Weiss, 1994), while our observations provided access to the actual work strategies of the observed professionalshighlighting in particular informal organisational aspects or the taken-for-granted and situational aspects of practice, that is, exploring the perspective of action (Heath et al. 2000). 
Table 1 provides an overview of the two phases of data collection.

Table 1: Overview of data material

\begin{tabular}{|c|c|c|}
\hline & Phase one & Phase two \\
\hline Data collection technique & Interviews & $\begin{array}{l}\text { Observational fieldwork including, } \\
\text { interviews, document studies and } \\
\text { informal talks. } \\
\text { Work and interaction, }\end{array}$ \\
\hline What was explored & Work and interaction & formal work setting - naturally \\
\hline Setting & Informal setting via phone & $\begin{array}{l}\text { occurring work } \\
\text { Various organisations and roles on }\end{array}$ \\
\hline Our informants & $\begin{array}{l}\text { Various organisations and roles on } \\
\text { the rig }\end{array}$ & $\begin{array}{l}\text { the rig } \\
\text { Six days in late } 2015\end{array}$ \\
\hline Period of data collection & Spring 2014 & 120 hours of data material \\
\hline Data material & Nine hours of data material & \\
\hline
\end{tabular}

A pilot study (phase one) on one rig provided 10 semi-structured interviews that lasted 45-60 minutes each. The interviews were fully transcribed and analysed using a thematic approach and reported in Steiro, Thevik, \& Albrechtsen (2017). Of the 10 informants, eight held management positions. The last two were experienced roughnecks, personnel handling manual tasks on the drilling floor, making the sample 'top-heavy'. It was important in phase two to work with a broader sample. The current study reports on data material from phase two and is based on six days onboard an offshore drilling installation located in the North Sea on the Norwegian continental shelf. The two authors carried out ethnographically inspired field studies, that is, observational work, semi-structured interviews, and document analysis. The pilot study (phase one) was performed by the first author, who also participated in the main phase of the project (phase two). The second author had full access to the transcribed interviews from phase one.

The main data collection period (second phase) consisted of a six-day field trip to the offshore installation providing both researchers with very rich and context-sensitive data from formal interviews, informal talks, and participatory observations - from meetings located inside the rig's administrative quarters to observational periods inside the driller cabin alongside the drilling floor. It was not natural, however, nor possible, to use the tape recorder during talks with the professionals. Consequently, we always went around together during data collection, which meant that we experienced the same events and situations, thus laying the grounds for a shared understanding of the empirical material, which was valuable during analysis. We spent 12-14 hours a day collecting data, making notes, and reflecting on the work observed. This type of collaboration enabled the researchers to verify and, in particular, challenge each other when collecting and analysing the data on the rig and likewise during further analysis upon returning. This was a great advantage in validating the observations and the data retrieved from interviews and talks in, for example, the coffee shop on-board the rig, on the drill floor, and the central control room (CCR), etc.

Bryman (2012) claims that both interviewing and taking proper notes can make it difficult to catch important information given by the informants. Therefore, being two interviewees enabled us to have one to lead and the other to concentrate on taking notes. However, this arrangement also allowed the 'number two' researcher to intervene and ask questions where appropriate, thus following up on themes for clarification purposes or probing deeper into some specific theme. Alvesson (2011) writes that one should be open for that meaning is produced in and through the interaction between respondent and interviewer. Also, with no tape recordings available, we focused on conducting debriefings between us by, for example, sitting down in the cabin or coffee shop and going through our notes and collectively reflect on recent events and impressions. This is important since Kvale and Brinkman (2009) claim that qualitative data 
undergo different stages of analysis; during the talks and interviews, after the talks and interviews, and finally, when back home, analysing the data and reporting from the findings.

Thematic analysis was adopted to analyse the interview material. This is a method for identifying, analysing, and reporting patterns (themes) within data (Braun \& Clarke, 2006). In contrast to other types of qualitative analysis (such as grounded theory, interpretative phenomenological analysis (IPA), or discourse analysis), thematic analysis is not bound to a theoretical or epistemological framework (Braun \& Clarke, 2006). Thematic analysis is performed through several steps and can be summarised in that the data is taken through the process of coding to establish meaningful themes. The actual analysis is not a linear process in the sense that the analyst goes backwards and forwards between the data and the codes, as well as between the themes and the codes. Our analytical approach was foremost driven by the researchers and theoretical interest concerning the research questions and can, therefore, be primarily classified as a deductive thematic analysis or a 'top-down' way (Braun \& Clarke, 2006). However, the analysis was also explorative, that is, incorporating elements of a bottomup analysis of the empirical material, thus also resembling what Alvesson \& Skoldberg (2009) describe as an abductive analytical approach.

\section{Results and discussion}

\section{Learning embedded within the PDSA}

We present an overview of the operations related to the PDSA concept. Figure 1 introduces the PDSA concept regarding foreseen and unforeseen actions. As we will argue, the organisation is continuously working to maintain the plan and avoid contingencies. Simultaneously, several of the informants point to both a centralised and formalised structure together with decentralised and situated communication as imperative means of operating efficiently and safely. You cannot have one without the other.

\section{Foreseen actions with tight couplings and machine bureaucracy adapted.}
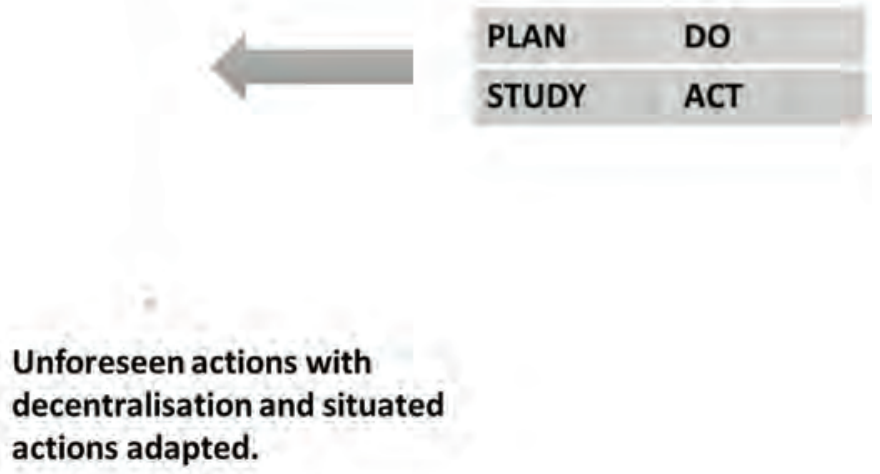

Figure 1. The PDSA concept seen with both foreseen and unforeseen situations

From Figure 1, we see the PDSA concept located with the analytical dichotomy of rig work. Arguably, the PDSA is an important means to tighten the grip between the foreseen and the unforeseen. Drilling operations are very strictly planned; however, what is expected in the formation (theoretical assumption) do not always turn out as expected, and adaptions often need to be made. Traditionally, adjustments are made primarily as a result of experiences related to 
'study', while operationally at the sharp end, there is empirical evidence for nuance, even though these are basically analytical phases. But still, we argue that, based on our data, it is natural to emphasise further 'do' through learning as done versus 'study' through learning as imagined.

The informants were very aware of this dualism, and it can be seen as a continuity activity (Hernes \& Irgens, 2013). Adaptions are not necessarily viewed as interruptions or deviations. They can also be viewed as a potential methodological challenge in our study since, according to Schein (1985), basic assumptions are best studied during a crisis. However, no such thing occurred during our stay, and the drilling installation had operated for a brief period with no documented large deviations or accidents. In Table 2, some central situations from our material are shown to support the argumentation for Figure 1 and to provide an overview of some empirical findings.

Table 2: Central findings and their explanation

\begin{tabular}{|c|c|c|c|}
\hline Situation & Findings & Context & Analytical \\
\hline $1 \mathrm{a}$ & $\begin{array}{l}\text { 'Are they dancing?' The driller } \\
\text { is not fully aware of what is } \\
\text { going on. He raises his hands } \\
\text { inside the drilling cabin. Then he } \\
\text { says, 'ok', pushing the stick } \\
\text { forward and pushing the drilling } \\
\text { tool further down the well. }\end{array}$ & $\begin{array}{l}\text { Observation inside the } \\
\text { drilling cabin. Two } \\
\text { service companies are } \\
\text { working on the well on } \\
\text { the drill floor and the } \\
\text { drilling crew sitting } \\
\text { inside the cabin is there } \\
\text { to act on their } \\
\text { instructions. }\end{array}$ & $\begin{array}{l}\text { By stating 'are they dancing', } \\
\text { the driller acknowledges not } \\
\text { knowing what is going on } \\
\text { outside the drilling cabin; the } \\
\text { other personnel present in the } \\
\text { drilling cabin do not remark or } \\
\text { comment, and it is our } \\
\text { impression that none of the } \\
\text { others knows what currently is } \\
\text { going on outside on the drill } \\
\text { floor. }\end{array}$ \\
\hline $1 \mathrm{~b}$ & $\begin{array}{l}\text { The driller calls the service } \\
\text { companies to enter the drilling } \\
\text { cabin. In this 'time out', the } \\
\text { driller tells them upfront that he } \\
\text { is not familiar with what is going } \\
\text { on outside and tells them to } \\
\text { update him on what to do next. }\end{array}$ & $\begin{array}{l}\text { Observation within the } \\
\text { drilling cabin. Same } \\
\text { situation as } 1 \mathrm{a}\end{array}$ & $\begin{array}{l}\text { After pushing the tool, without } \\
\text { fully understanding what is } \\
\text { going on, he switches on the } \\
\text { public announcement (PA) } \\
\text { system and asks the service } \\
\text { companies to come to the } \\
\text { drilling cabin. He then asks } \\
\text { them to give him direct orders. } \\
\text { The situation is atypical since } \\
\text { the driller will be fully in } \\
\text { charge, operating from the } \\
\text { drilling plan and not taking } \\
\text { guide/orders from the drilling } \\
\text { floor. }\end{array}$ \\
\hline 1c & $\begin{array}{l}\text { A good supervisor responsible } \\
\text { for planning the well, but not } \\
\text { directly involved in the } \\
\text { operations enters the drilling } \\
\text { cabin and monitors the situation. } \\
\text { He tells us that he has informed } \\
\text { the two service companies that } \\
\text { one of them must take the lead in } \\
\text { the operation. The service } \\
\text { companies have acknowledged } \\
\text { this, and one of the persons said } \\
\text { he would do it. The good } \\
\text { supervisor turns to us researchers } \\
\text { and, unsolicited states that 'this } \\
\text { is what it is all about all the time: } \\
\text { planning and communication'. }\end{array}$ & $\begin{array}{l}\text { Observation in the } \\
\text { drilling cabin and talks } \\
\text { with the good } \\
\text { supervisor. } \\
\text { Linked to the same } \\
\text { situation as 1a and 1b }\end{array}$ & $\begin{array}{l}\text { It is interesting to see situations } \\
1 \mathrm{a} \text { and } 1 \mathrm{~b} \text { and that } 1 \mathrm{c} \text { is linked } \\
\text { but independent. The good } \\
\text { supervisor was not in contact } \\
\text { with the driller, as we could } \\
\text { observe before entering the } \\
\text { drilling cabin. The interesting } \\
\text { thing is that there are two } \\
\text { independent approaches to the } \\
\text { same situation. }\end{array}$ \\
\hline
\end{tabular}




\begin{tabular}{|c|c|c|c|}
\hline 2 & $\begin{array}{l}\text { 'Did it go well?' Reply made } \\
\text { calmly in response, 'It went as } \\
\text { planned.' }\end{array}$ & $\begin{array}{l}\text { Observation overheard } \\
\text { in the locker room. A } \\
\text { person coming down } \\
\text { from the offices from a } \\
\text { small service company } \\
\text { meets and greets a } \\
\text { colleague coming in } \\
\text { from the 'outdoors'. } \\
\text { Eagerly ask him about } \\
\text { the status. The } \\
\text { colleague replies what } \\
\text { we interpret as } \\
\text { confidence in a calm } \\
\text { tone, 'It went as } \\
\text { planned'. }\end{array}$ & $\begin{array}{l}\text { We see that following plans is } \\
\text { a way of doing business and } \\
\text { does not account for great } \\
\text { excitement when going as } \\
\text { planned. First, when taking } \\
\text { notes, we just found it as } \\
\text { something amusing. However, } \\
\text { looking back and looking into } \\
\text { other observations, we find it } \\
\text { interesting. }\end{array}$ \\
\hline 3 & $\begin{array}{l}\text { This is not directly linked to a } \\
\text { particular situation but is a } \\
\text { reflection on different situations. } \\
\text { The drilling supervisor reflects } \\
\text { on how, following the drilling } \\
\text { crew. 'I am always considering } \\
\text { the mood and feeling within the } \\
\text { drilling team.' When they are in } \\
\text { good spirit, I try to keep them on } \\
\text { tip-toe to focus their efforts. } \\
\text { When in bad spirit, I tell them } \\
\text { that they are good. I see myself } \\
\text { as a football manager'. }\end{array}$ & $\begin{array}{l}\text { Situation } 3 \text { is more } \\
\text { general considerations } \\
\text { and happened before } \\
\text { situation 1a-1c. }\end{array}$ & $\begin{array}{l}\text { In-depth interview with the } \\
\text { drilling supervisor. }\end{array}$ \\
\hline 4 & $\begin{array}{l}\text { 'We are constantly trying to } \\
\text { update the plans to be better } \\
\text { '(drilling superintendent). This is } \\
\text { something they do between } \\
\text { operations and incorporate in the } \\
\text { new plans that need to be } \\
\text { quality-assured. 'The procedure } \\
\text { is fresh product; it would have to } \\
\text { be available here and now. A } \\
\text { library with procedures does not } \\
\text { work for me '(drilling } \\
\text { superintendent). }\end{array}$ & $\begin{array}{l}\text { Situation } 4 \text { is more of a } \\
\text { consideration of the } \\
\text { role of plans. }\end{array}$ & $\begin{array}{l}\text { In-depth interview with the } \\
\text { drilling superintendent. The } \\
\text { drilling superintendent is } \\
\text { working onshore and not } \\
\text { directly following up on the } \\
\text { drilling operation. }\end{array}$ \\
\hline
\end{tabular}

In phase two, we started with an interview with the offshore installation manager (OIM) at the rig. He explained the systems they have for learning and knowledge transfer to be a way of storing the memory of the organization. This can be seen as a form of procedural memory (Huber, 1991; Crossan et al. 1999). He showed us illustrations of the system and pointed to the visual management board. It is a board showing numerous indicators of how the rig is performing. These results are hanging very visible in the office landscape and close to the main meeting room. The same numbers are also reported to the licensee owners. The OIM said that a lot was invested in the organisation regarding training and team building. There is a strong demand for knowledge transfer reporting, both what works well and what does not work well. According to the OIM, the operating company was perceived as quite thorough in the initial days when the rig was constructed. At the time, the operator company took a controlling approach also into operations. However, the drilling entrepreneur had shown initiative, been very open-minded, and as a consequence, trust among the actors increased. The OIM claimed that; 'Now they are confident that we are telling them if there are some problems as early as possible. Sætren and Laumann (2014) found trust to be important in high-risk operations during 
technological change. The OIM further pointed out that the management team had found common ground on how to operate. Their work is structured based on the PDSA concept; however, they actively adhere to an informal communication style, including quite a lot of humour. Of course, this might differ from crew to crew, but there is an informal sense to the formality of plan-based work practice. 'You will see on the meeting that there is no agenda presented. But there is a well-defined and known structure. All are familiar with it'. The OIM informed us that he participated in approximately 70 meetings during his 14-day offshore period. He explained that the drilling entrepreneur had adopted a performance-based management structure. Drilling rig operations were to be centred around the concept of PlanDo-Study-Act. So PDSA is a framework for planning that also enables communication, where communicative ways of conducting collaborative work cannot always be laid down in a formalised and standardised procedure.

The morning meeting between the onshore organisation and offshore installation is the most important day-to-day link between them (Haavik, 2011). We witnessed a highly structured but also flexible meeting arena with subsequent space and openness to discussions on the rig side. Onshore, only the drilling superintendent was actively talking. However, 25-30 persons were also present and positioned behind the superintendent. The idea is that they are available if and when specific topics occur and to provide information and begin contingency planning if there are some reported deviations.

We also participated in the Sunday morning safety meeting for all personnel not operating the rig (the same meeting would be held after dinner and handover for the personnel who had been working). Due to cost-cutting, we learned that the meeting was reduced from 60 minutes to 30 minutes. The camp boss provided soda for all. The atmosphere was positive-a highly structured meeting with room for questions and good humour, reinforcing the positive atmosphere. There was room for interaction, and management encouraged questions in the safety meeting. The meeting ended with the company man explaining the challenges concerning well number two. There was reportedly more subsea clay than anticipated. However, both the onshore engineers and the crews offshore had managed to drill around the problem. The company man explained the integration of knowledge and joint efforts. 'This operation has been a success. We [the operator company] offer a wildlife food evening'. Sætren and Laumann (2014) also found a casual atmosphere and a respectful way of speaking to each other as the most important factor to facilitate good communication. We found the same in our interviews and observation. Plaskoff (2011) points out that an important management task is to provide valuable direction in the organisation and see this as an important feature for organisational learning.

The operator company was not so used to drilling entrepreneurs' involvement in planning. They had been sceptical in the beginning, but both informants from the drilling company and the operator company stated that this involvement was perceived as very valuable. De Geus (1988) observed that scenario planning was not only about planning but that it was equally important to get various people to talk actively to each other. Based on our observations, it struck us that in our interviews and conversations with the crew about what success meant on the rig, two key aspects were mentioned frequently; plans and communication. Several people mentioned these, some claiming both aspects as equally important, some put the efforts on plans, others on communication. However, we also observed that not all the teams or groups of personnel were fully in the loop regarding both plans and communication. The central control room (CCR) was placed under the deck quite a distance from rig operations. The two control room operators stated that they communicated with everyone within the rig. However, and despite their background in drilling, they did not have access to the drilling plan. 'This makes it difficult to assist. A driller can thus expect that CCR is more than what we possibly have the opportunity 
to be'. The lack of access to the daily drilling program was also confirmed later by another control room operator whom we interviewed. Huber (1991) claims that the distribution of information influences the degree of organisational learning as it provides more and different interpretations of the same information. The drilling program is thus very important but seemingly not important enough for the control room to have access to and therefore not in the loop. The drilling program's importance is highlighted by several informants in our study.

Another example was overheard in the locker room while we were shifting before entering the rig's deck area to visit the driller cabin to observe. An employee from the service company 'rushed' eagerly towards a colleague who just arrived from the drilling deck. Clearly excited about what his colleague in orange will convey, he asks with anticipation, 'Did the job go well?' The colleague responded calmly: 'It went as planned.'

A roughneck from phase one pointed out his contribution regarding safety. 'The most important factor...must be that I report if something might be dangerous. One example is the mud weight. I cannot go easy on that, but make sure that I give accurate information on the mud weight'. Several of the informants from both phase one and phase two stressed the importance of doing things right and following the procedures. It is more important to do things right than fast. Right means that one is prepared according to the plan. The right equipment is in place. The driller explained that the assistant driller is responsible for preparing tools and equipment for the next phase. If this is not done properly, the operation will halt. One toolpusher interviewed in phase two reported that procedures together with good cooperation were the most important factors for being proactive. Regarding the drilling plan and procedures, the drilling superintendent commented that the planning documents should ideally be like this 'is not too voluminous, based on best practice, and communicated properly'.

Several informants' states that it was better for all to report if a tool was dropped in the well; it was important. This was mentioned by several managers as very important. The rationale could be explained by: 'Then we can handle it and do not get surprised later' (company man). JerezGomez et al. (2005) point to four factors regarding the ability to learn: engagement from the management, system perspective, openness, and experimentation. In this example, openness is the key. Simultaneously, not being punished for a mistake is about clear engagement from the management clearly demonstrating no discrepancy between its word and its practice regarding the reporting of mistakes (Argyris \& Schön, 1978). No fear was reported. However, Haavik (2010) reported a lot of trust horizontally but less trust vertically. The latter was attributed to a lack of openness in expressing different opinions since it could be a barrier to promotions (Haavik, 2010). A basic assumption in continuous improvement initiatives is to create an organisational learning environment (Bessant et al., 2001; Wu \& Chen, 2006).

On the operator level, toolbox talks were viewed as the most important tool for safety. It is performed for every job and involves all parties. The purpose is to ensure a safe and efficient operation by assigning tasks and examining known risks associated with the operation. After the action, an after-action review is performed. Regarding procedures, it assesses their execution, the resources, and the risk, asking what went well, how to improve, and the lessons learned. These are put into a one-pager and becomes part of the PDSA system.

\section{Drilling work and the importance of following the plan}

Operational morning meetings that involve both onshore and offshore teams are intriguing to study since they represent a unique opportunity to gain insight into how the operations are planned in advance, communicated, coordinated, and carried out. Specifically, operational morning meetings are regarded as the primary arena for collaboration between the onshore rig teams, the offshore drilling organisation, and representatives from the service companies 
onshore (Haavik, 2011; 3-4). The onshore teams possess a variety of resources in the form of expertise, software, time to perform calculations, produce documentation, and come up with coherent and consistent interpretations with theories, models, and governing documentation for drilling. Thus, the onshore teams are specialists in designing and managing plans. On the other hand, the offshore crew has their foremost strengths in proximity to operations, their historical experience from other wells, and their experience and competence in handling variability at the moment. This empirical context thus provides a variety of aspects regarding drilling operations (Haavik, 2011), particularly how plans are viewed as imperative for accomplishing successful rig operations from the perspective of management.

However, based on our observations, we also find it instructive to note that the offshore crew referred to above manifests itself in two analytically distinct yet interdependent organisational entities. Firstly, you have the local management offshore, for example, the oil installation manager (OIM) and the drilling section leader (DSL). Secondly, roles related to the drilling work include the driller, assistant driller, mud-logger, and roughneck. Although their tasks and responsibilities differ, one sees some common characteristics of working within a formal and plan-based organisational context. Consider the following examples.

\section{Formalised, yet loosely coupled meeting arenas, 'let's get it right'}

Let's look at the operational morning meeting where both onshore and offshore management are present. The operating company hosts the morning meeting led by their representative onboard the rig, the 'company man'. The contractor company rig management participants include the oil installation manager (OIM), drilling section leader (DSL), technical section leader (TSL), and safety officer. The rig's assistant manager and HSE coordinator also participate from ashore via video. During this meeting, the company man relates primarily to his leader ashore, the drilling superintendent, who formally is the highest-ranking person present. Along with the operating company are several subcontractors who have placed themselves around and behind the drilling superintendent. Some of them are not visible in the video feed. The subcontractors are not usually active during meetings, participating only if questions related to their areas of responsibility and expertise emerge.

The morning meeting begins with the company man providing the status of rig operations followed by short briefings from some of the contractor employees present. The company man continues by asking if anyone has questions, and if there are no questions at the moment, the OIM takes over commenting on the focus of the week, that is, 'toolbox talk'. According to the OIM, daily toolbox talks are very important; 'In terms of safety, toolbox talk is the most important tool' (OIM). The company man continues to brief:

There are no rejected joints so, that's fine. We also hope for a steady pace now with steady joints. It's time-consuming, but it's a delicate process. It is going in the right direction. Are there any questions about the operations? (Company man).

The drilling superintendent continues after uttering ' $n o$ ' in general terms about the progress of operations, which is a recap of prior information during the meeting. The OIM takes over once more and comments on the plan for today. 'We will lay down the port forward crane'(OIM), which is endorsed by the drilling engineer and company man. The drilling engineer then comments first on the equipment needed for Thursday, referring to the standby vessel in particular; 'There is maintenance on Thursday on $x x x$. We thus need to have a replacement' followed by 'There are no flights today. The crew change flight will be tomorrow' (drilling engineer). When the morning meeting is about to end, we observe a loose and somewhat facetious tone between the parties, initiated by the company man. However, the meeting formally ends some moments later with the following comments: 
Basically, we have all the equipment needed to finalise the well (company man).

Let's get it right (drilling superintendent).

Similarly, we observed a somewhat similar distinct meeting structure when we attended the work permit meeting. The meeting started at 16.00 hours; seven persons were present in the room, including OIM, safety officer, LSD, TSL, and the rig's internal coordinator. The OIM initiates by saying, 'Twenty-one safe talks' followed by '... weekly safety focus, tubular handling'. This very brief introduction sets the stage for the subsequent going through of observation reports, one example being; '... a roll of paper placed on top of the light wall in men's toilet on B deck. Action taken: removed paper roll' (OIM). It strikes us that the work permit meeting is structured around the varying persons participating at expected times. Nevertheless, it is the OIM who is most active, commenting on what is defined as good reporting; 'Observed good safety culture among roughnecks'. The OIM informs that this has to do with roughnecks explicitly asking for permission to enter a zone on the rig. The OIM continues with a briefing on the general alarm planned for Sunday morning, followed by a discussion on what type of alarm they should initiate. The discussion then continues, focusing on the number of people presently involved in upper completion at the rig floor. Thus, safe talks are imperative to ensure proper and safe coordination among the involved personnel. Furthermore, the safety officer comments that the rig deck seems quite untidy, something that needs sorting out. The work permit meeting comes to an end with the OIM commenting on a fire alarm earlier that day; an alarm triggered, it seems, by an apprentice flushing water on some gas detector outside. This incident causes laughter among those at the meeting.

\section{Acknowledging situatedness; 'are they dancing?'}

Consider the following example (see also Table 2) occurring on the drill deck during good completion: Two service companies are currently operating on the drill deck, and we are standing inside the driller cabin behind the driller and assistant driller, observing the action. The driller and the assistant driller are now responsible for serving and assisting the service companies on deck. We are making small talk with both the driller and assistant driller when, after a while, the driller, visibly frustrated or annoyed, seems not to know what is happening on the drill deck. It turns out that he is unsure of where the service companies are in the drilling program resulting in the driller exclaiming in the direction of the assistant driller, 'Are they dancing?' and throwing out his arms. The driller continues by saying, 'Yes' and then pulling the joystick forward, controlling the tool supporting the service companies' work. Shortly later, the driller halts. He grabs the microphone and summons everyone on the drill deck inside the driller cabin, where he informs them that he has lost track of their progress and that they need to inform him right now. The driller is updated, and after a few minutes, the teams operating on the drill floor is back up and running.

Another episode occurred halfway through the conversation with the safety officer. While we chatted, an operator from the control informed us via the Public Announcement (PA) system that a fire alarm was activated, followed by the operator informing the crew that all work on the rig needs to stop while the alarm is investigated. After a few minutes, the PA system calls off the alarm, and work resumes. During our talk with the two operators in the rigs' control room, they confirmed what revealed during the work permit meeting earlier, that an apprentice who inadvertently rinsed water on a sensor caused the fire alarm. The operators told us that for all alarms, 'We always send out someone to check'.

Furthermore, during our talk with the drilling section leader (DSL), we discussed how important it is that employees feel secure about how they perform their jobs. This was something the DSL was particularly concerned with in terms of experience and learning. The point is, according to 
DSL, 'I must be able to say that this is not good enough, without them out here expecting to get fired. That said, people work damn good here' (DSL). According to the DSL, this varies a lot between different countries; however, in this company and on this particular rig, the authority gradient is reportedly quite low. DSL continues to reflect on how he prefers to relate to subordinates by pointing to what he tends to do concerning pre-job meetings: 'I'm bored when things are routine. Then I go in and try to influence with something new. One is safe as long as one is not in a sleep state' (DSL). He occasionally meets up at these pre-job meetings uttering comments like 'This is not working', the idea is to basically 'kick off some thoughts among the participants. The DSL tells us that what is most important is to do things the correct way from the beginning, meaning that performing work quickly is not considered imperative onboard the rig.

Arguably, key dimensions of successful reliance on plans and procedures (as resources) for action in offshore drilling is the trust via transparency among employees, regardless of their place in the professional hierarchy. An example of how trust can be facilitated is provided by the company man (operator company) linked to losing a utility tool in the well, which will be problematic only if the person responsible does not speak up immediately. This transparency is extremely important to prevent major problems later. By drawing on the work of Suchman (1987) related to plans as resources for action, following plans per se and situated work during drilling operations are two sides of the same matters. For example, we have seen above that formalised meetings indeed drive the agenda; however, the content of meetings is still situated per se. Arguably, the somewhat casual tone within meetings facilitates the loosening of couplings in Perrow's (1999) terms. Likewise, actual work out on the sharp end, on the rig deck, shows similar characteristics when the driller halts work, calling for an update. An update that illustrates situatedness can be a key dimension, even though the drilling plan is the overarching management tool.

\section{Conceptualising the learning dualism-learning as an integrated part of a practice}

Figure 2 is intended to analytically highlight the importance of understanding learning processes on the drilling rig as anchored in naturally occurring and hence real work practicea work practice that primarily relies on 'the plan' as a resource for what is continuously performed. At the same time, this work practice is characterised by inherent variation, including local adaption, to be meaningful for the professional actors involved. Figure 2 illustrates the duality of learning involved when utilising, for example, the drilling plan as a resource for local action on the drilling floor. Based on PDSA, including the four stages as a framework for organisational learning and, for example, updating the drilling plan-that is, learning per se, we argue for the relevance of also recognising conceptually an explicitly situated dimension related to learning on the drilling rig. This is the learning that occurs based on the need for local adaptions, that is, learning as done, as a parallel to Hollnagel (2014) and work as done. Similarly, we argue that learning as imagined reflects how PDSA is currently intended to function, which does not cover how learning on the drilling rig manifests itself through actual practice. It is worth pointing out that these are two parallel dimensions that are mutually dependent on each other, something Hollnagel (2014) also points out through the intention with safety I and safety II, that is, respectively, work as imagined and work as done. 
Figure 2. PDSA conceptualised concerning the duality of learning

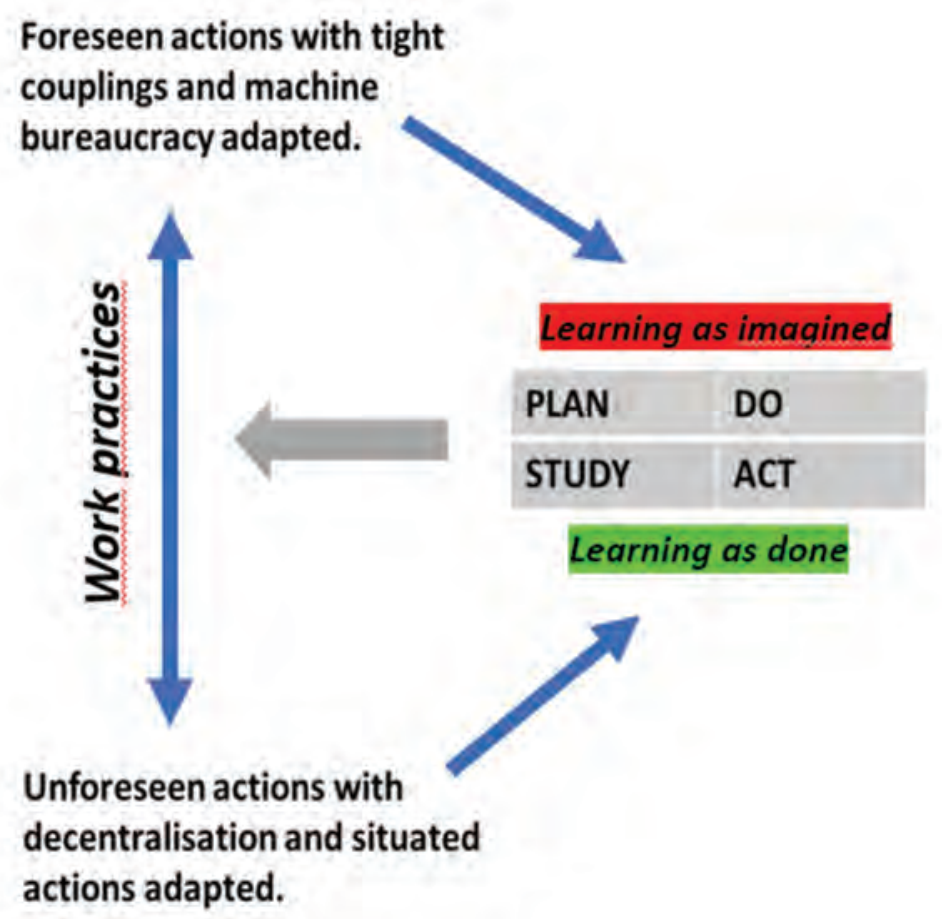

There is an analytical coupling between learning as imagined and expected actions (and outcomes) characterised by tight couplings as Perrow (1999) describes the traditional machine bureaucracy. Simultaneously, learning as done is grounded in actions characterised by a greater degree of uncertainty, that is, unforeseen actions that are traditionally also linked to decentralisation (Perrow, 1999) and situatedness (Suchman, 1987, 2007). These two learning dimensions are thus to be regarded as interdependent phenomena. Thus, the degree of one or the other learning dimension to count for actual organisational learning, as it is analytically reflected in the vertical dimension work practices (Figure 2), may vary from situation to situation. For applied purposes, it is a matter of the PDSA framework influencing learning through practice, at the same time as PDSA is also influenced by the same learning-based work practices.

\section{How to further enable learning in drilling organisations}

As observed and discussed earlier, planning and communication are essential. These can be seen as complementary (Bolman \& Deal, 1989). Learning is essential for improvement, as seen from the theory. A toolpusher provided an example of the importance of a drilling entrepreneur supporting the operator at any time. 'One example is from a casing job in May. The equipment that was necessary for the operation was not assembled correctly onshore before shipping it offshore. This was discovered when the containers with the equipment arrived offshore. The lessons learned were updated in the procedures with a "pre-check" list before sending it offshore'. Here we see that these lessons learned as part of the PDSA system resulted in the new procedure, thereby embedding the learning into practice. The drilling entrepreneur's operative level gave the input, and the operator used the input to update the procedure for this and other company rigs. Imai (1986) points to the importance of spreading the improvements. Otherwise, the results will remain local and the industry not optimised (Sobek \& Smalley, 2008).

'We are constantly trying to update the plans to be better' (drilling superintendent). This is something they do by and between operations. 'The procedure is fresh product; it would have 
to be available here and now. A library with procedures does not work for me' (drilling superintendent). Procedural memory refers to the stored experience, knowledge, and skills that are reproduced on a routine basis by organisational members (Cohen, 1991; Moorman and Miner, 1998; Singley \& Anderson, 1989). In machine bureaucracies like a drilling organisation, the drilling superintendent's views are in line with the view of institutionalising knowledge (Crossan et al. 1999). A basic assumption in continuous improvement initiatives is to create an organisational learning environment (Bessant et al., 2001; Wu \& Chen, 2006). One challenge is how much information should be put in the drilling program; precise information without being too voluminous. Another aspect is the understanding of the drilling program. The drilling superintendent points to a solution that works for him: 'We're talking through what I have written. It's about doing putting others` in a favourable position’ (Drilling superintendent).

After action reviews out on the rig, the engineer writes down the experiences. 'We can look it over and have it checked out properly' (drilling superintendent). The drilling superintendent meets with the construction manager the day before travelling out to the offshore site for a shift period of two weeks (the offshore rotation in Norway is two weeks offshore and four weeks onshore). The purpose is to discuss learning and challenges while the drilling manager return from his four-week leave. Challenges related to this are all about: 'To close the loop completely' (drilling superintendent). Get engineers onshore to utilise the learning database and to improve plan and procedures. 'It must be easy for the driller who sits in the chair' (drilling superintendent). 'We encourage writing a "Tally" (a note or correction in the daily drilling plan) and to provide this to the engineer.' 'The procedure must function in practice' (drilling superintendent). However, it was claimed from the drillers and driller assistants that what they had written not always was taken into the procedures. The drilling superintendent responded that this was correct and that there was a delay in time. The onshore organisation needed to evaluate and assess risk and have its quality assured. This could take time, but of course, it also led to frustration among the operating core. The way forward was to arrange their own meetings, collect all the lessons, and feed the newly acquired knowledge into procedures while, at the same time, explaining improvement suggestions that had not been taken into account due to practical or safety considerations. Hopkins (2000) found that engineers play a crucial role in assessing new suggestions for improvement. Some of the frustration reported from the offshore side could also be seen not only as a time frustration but also as a lack of feedback and explaining why something is not changed due to the request from the personnel operating offshore. Husemoen (1997) found that engineering and operations have different perspectives. However, these perspectives need to be integrated, although they also can challenge each other to find a better-shared solution. Physical proximity was found to be a precondition for success. Today, with modern videoconference equipment, physical distance can be reduced. Another precondition for success in Husemoen's study was mutual trust. Trust has also been underlined by Sætren \& Laumann (2014). Better feedback was needed. A lack of integrations onshore and offshore can lead to practical drift (Snook, 2000). Practical drift can be seen as the discrepancy between work as planned and work done. A lack of feedback can create frustration with the system - blaming the system for procedural practices that obstruct the offshore team's individual insights and experiences are adapted in the procedures (March \& Olsen, 1975; Kim, 1998).

Haavik (2011) points out that the onshore team has rich resources in the form of expertise and software, while the offshore crew has strengths in its proximity to the operations and their historical experience from other wells. The PDSA methodology can be seen as following similar steps like a scientific methodology (Sobek \& Smalley, 2008; Lillrank \& Kano,1989). That would also imply feedback on suggested improvements. 


\section{Concluding remarks}

We have seen that mutually good communication is essential for both operations and learning. Drilling demands thorough planning and rigorous plans. However, changes occur, and unforeseen incidents happen. Therefore, not everything goes according to plan, yet the plans are still not abandoned per se. However, more interaction and follow-up is needed. We see that foreseen actions demand tight couplings. Drilling operations operate within a machine bureaucracy well suited for handling and managing tight coupling. However, during unforeseen actions, more decentralisation and adaptation of situated action is needed. We see that good communication practices must be established during normal operations and extended into more demanding phases of the operations (Lagadec, 1993).

The plan-do-study-act concept (PDSA) used on this rig contributes in both situations. Open and lateral communications also contribute, in particular, to problem-solving during unforeseen actions. But open and lateral communication during the foreseen actions creates the foundation for communication during unforeseen situations with a high degree of complexity. This is done not only on the organisation's top-level but also is performed vertically, i.e., social interaction throughout the organisation. Both formal and informal aspects play a crucial role in understanding learning as imagined and learning as done. This is important for avoiding practical drift (Snook, 2000) and ensuring safe and successful operations. Therefore, the current study can be seen as input to reducing practical drift. The key is establishing good practices during normal and routine operations, seeing planning as a means of executing and learning, communication as means of oiling the machinery and providing feedback into the planning processes. The PDSA system in the current study reinforces these processes.

This paper thus recognises the nuances associated with learning and how offshore learning is strongly linked to the execution of planning. It is not new that planning per se is re-evaluated and adjusted; it is the way this is done and how this practice-based duality also implies learning, which is particularly interesting and relevant to conceptualise. This is because continuous variation inherent within real work practice is both a consequence of and a prerequisite for learning on-board the drilling rig.

\section{Acknowledgements}

This work has been performed as part of the project 'Learning from successful operations' and is sponsored by the Research Council of Norway through the PETROMAKS 2 research programme, grant number 228144/E30. No conflict of interest is identified.

\section{References}

Alvesson, M. \& Skoldberg, K. (2009). Reflexive methodology. New vistas for qualitative research. London. Sage. Alvesson, M, (2011). Intervjuer: genomförande, tolkning och reflexivitet. Liber.

Argyris, C. \& Schön, D.A. (1978). Organizational Learning: A Theory of Action Perspective. Reading, MA: Addison-Wesley.

Argyris, C. \& Schön, D.A. (1996). Organizational Learning II: Theory, Method, and Practice: Theory, Method, and Practice. London. FT Press.

Berger, A. (1997). Continuous improvement and kaizen: standardisation and organisational Designs. Integrated Manufacturing Systems, 8, 110-117 doi.org/10.1108/09576069710165792

Bessant J., Caffyn, S., \& Gallagher, M. (2001). An evolutionary model of continuous improvement behavior. Technovation, 21, 67-77.

Bourrier, M. (1998). Elements for Designing a Self- Correcting Organisation: Examples from Nuclear Power Plants. In: Hale A \& Baram MS (eds.), Safety

Management. The Challenge of Change. Oxford: Pergamon.

Brandi, U. \& Elkjaer, B. (2011). Organisational learning viewed from a social learning Perspective. Handbook of organisational learning and knowledge management, 21-

41. 
Braun, V. \& Clarke, V. (2006). Using thematic analysis in psychology. Qualitative research in psychology, 3(2), 77-101. DOI: 10.1191/1478088706qp063oa

Bryman, A. (2008). Social research methods. Oxford: Oxford University Press.

Burns, T.E. \& Stalker, G.M. (1961). The management of innovation. University of Illinois at Urbana-Champaign's Academy for Entrepreneurial Leadership Historical Research Reference in Entrepreneurship.

Cyert, R.M. \& March, J.G. (1963). A behavioral theory of the firm. Englewood Cliffs, NJ.

Cohen, D. (1991). Individual learning and organisational routine: Emerging connections. Organizational Science 2(1): 135-139. doi/pdf/10.1287/orsc.2.1.135

Crossan, M.M., Lane, H.W., \& White, R.E., (1999). An Organizational Learning Framework: From Intuition to Institution. The Academy of Management Review, 24, 522-537.

De Geus, A, (1988). Planning as learning. Harvard Business Review 66(2): 70-74.

Deming, W.E. (2000). Out of the crisis. Cambridge, Mass., MIT Press.

Goh, S. \& Richards, G. (1997). Benchmarking the learning capability of organisations. European Management Journal, 15, 575-583. doi:10.1016/S0263-2373(97)00036-4

Heath, C., Knoblauch, H. \& Luff, P. (2000). Technology and social interaction: the emergence of workplace studies. British Journal of Sociology, 51(2): 299-320.

Hellesøy, O.H. (Ed.). (1985). Work Environment, Statfjord Field: Work Environment, Health, and Safety on a North Sea Oil Platform. Oslo: Universitetsforlaget.

Hernes, T. \& Irgens, E.J. (2012). Keeping things mindfully on track: Organisational learning under continuity. Management Learning, doi: 10.1177/1350507612445258.

Hollnagel, E. (2014). Safety-I and Safety-II. Farnham: Ashgate.

Hollnagel, E. (Ed.). (2013). Resilience engineering in practice: A guidebook. Ashgate Publishing, Ltd.

Hollnagel, E. (2009). The ETTO principle: efficiency-thoroughness trade-off: why things that go right sometimes go wrong. London: Ashgate Publishing, Ltd.

Hopkins, A.H. (2000). Lessons from Longford: The Esso gas plant explosion. Sydney: CCH Australia Limited.

Huber, G.P. (1991). Organizational Learning: The Contributing Processes and the Literatures. Organisation Science, 2, 88-115.

Husemoen, M.S. (1997). Bridging operation and design. The encounter between practical and discipline-based knowledge in offshore platform design.

Haavik, T.K. (2011). Chasing shared understanding in drilling operations. Cognition, Technology \& Work. 13(4), 281-294. DOI: 10.1007/s10111-010-0166-z

Haavik, T.K. (2010), Making drilling operations visible: the role of articulation work for organisational safety. Cognition, Technology \& Work, 12(4), 285-295. Doi:10.1007/s10111-010-0139-2.

Imai, M. (1986). Kaizen (Ky'zen): the key to Japan's competitive success. Random House.

Jerez-Gomez, P., Céspedes-Lorente, J. \& Valle-Cabrera, R. (2005). Organisational learning capability: a proposal of measurement. Journal of Business Research, 58, 715-725. http://dx.doi.org/10.1016/j.jbusres.2003.11 .002

Kim, D.H. (1998). The link between individual and organisational learning. The Strategic Management of Intellectual Capital, 41-62.

Kvale, S. \& Brinkmann, S. (2009). Interviews: Learning the craft of qualitative research Interviewing. London: Sage.

Lagadec, P. (1993). Preventing chaos in a crisis. Maidenhead: McGraw-Hill.

LaPorte, T.R., \& Consolini, P.M. (1991). Working in practice but not in theory: theoretical challenges of 'highreliability organisations. Journal of Public Administration Research and Theory, 1(1), 19-48.

March, J. G. (1991). Exploration and Exploitation in Organizational Learning. Organisation Science, 2(1), 71-87. Doi:10.1111/ijmr.12076.

March, J.G., \& Olsen J.P. (1975). The uncertainty of the past: organisational learning under Ambiguity. European Journal of Political Research, 3, 147-171.

Mintzberg, H. (1979). Structures in fives. Prentice-Hall.

Moorman, C. \& Miner, A.S. (1998). The convergence of planning and execution: Improvisation in new product development. Journal of Marketing 62(3): 1-20. DOI: 10.2307/1251740.

Morgan, G. (1980). Paradigms, metaphors, and puzzle solving in organisation theory. Administrative science quarterly, 605-622.

Morgan, G. (2006). Images of Organization. Sage.

Morgan J.M. \& Liker, J.K. (2006). The Toyota product development system. The Productivity Press.

Nonaka, I. \& Konno, N. (1998). The concept of 'ba': Building a foundation for knowledge creation. California management review, 40(3), 40-54.

Nonaka, I. (1994). A Dynamic Theory of Organizational Knowledge Creation. Organisation Science, 5, 14-37. DOI: $10.1287 /$ orsc.5.1.14 
Ose, G. O., \& Steiro, T. J. (2020). An Analytical Framework for Resilience Exemplified With a Real-Time Operational Center. ASCE-ASME J Risk and Uncert in Engrg Sys Part B Mech Engrg, 6(1).

Lillrank, P.M. \& Kanō. N. (1989). Continuous improvement: quality control circles in Japanese industry. Center for Japanese Studies University of Michigan.

Pedler, M., Burgoyne, J. \& Boydell, T. (1999). The learning company: A strategy for sustainable development (3rd ed.). McGraw-Hill.

Pedler, M., Burgoyne, J. \& Boydell, T. (Eds.) (1990). Self-development in organisations. McGraw-Hill.

Perrow, C. (1984). Normal Accidents: Living with High-Risk Technologies. Basic Books.

Plaskoff, J. (2011). Intersubjectivity and community-building. In: M. Easterby-Smith, \& M. A. Lyles (Eds.), Handbook of organisational learning and knowledge management (2nd ed., pp. 199-223). Wiley.

Rasmussen, J. \& Svedung, I. (2000). Proactive Risk Management in a Dynamic Society. Swedish Rescue Services Agency.

Rosness, R., Grøtan T.O., Guttormsen G., Herrera, I.A., Steiro, T., Størseth, F., Tinmannsvik, R.K. \& Wærø, I. (2010). Organisational Accidents and Resilient Organisations: Six Perspectives. SINTEF.

Shook, J. (2008). Managing to learn: Using the A3 Management Process to Solve Problems, Gain Agreement, Mentor and Lead. Cambridge. MA: Lean Enterprise Institute.

Simon, H. (1991). Bounded rationality and organisational learning. Organization Science, 2(1), 125-134.

Singley, M.K. \& Anderson, J.R. (1989). The Transfer of Cognitive Skill. Harvard University Press.

Snook, S.A. (2002). Friendly fire: The accidental shootdown of US Black Hawks over Northern Iraq. Princeton University Press.

Sobek, D.K. \& Smalley, A. (2008). Understanding A3 thinking: a critical component of Toyota's PDCA management system. CRC Press.

Steiro, T. J., Thevik, A., \& Albrechtsen, E. (2017). On Formal and Informal Factors: Enabling Learning for Safe Offshore-Drilling Operations. International Journal of Management, Knowledge and Learning, 6(2), 85106.

Suchman, L. (2007). Human-machine reconfigurations: Plans and situated actions. Cambridge University Press.

Suchman, L.A. (1987). Plans and situated actions: the problem of human-machine communication. Cambridge: Cambridge University Press.

Sætren, G.B. \& Laumann, K. (2015). Effects of trust in high-risk organisations during technological changes. Cognition, Technology \& Work, 17(1), 131-144. DOI 10.1007/s10111-014-0313-z

Von Krogh, G., Ichijo, K. \& Nonaka, I. (2000). Enabling knowledge creation: How to unlock the mystery of tacit knowledge and release the power of innovation. Oxford University Press.

Weiss, R.S. (1994). Learning From Strangers: The art and method of qualitative interview studies. Free Press.

Womack, J.P. (1990). The machine that changed the world. Simon and Schuster.

Wu, C.W. \& Chen, C.L. (2006). An integrated structural model toward successful continuous improvement activity. Technovation, 26, 697-707. http://dx.doi.org/10.1016/j.technovation.2005.05.002 